\title{
Short communication \\ Status of methane gas emission from paddy fields in Nepal
}

Madhab Joshi

Senior Agronomist, NARC (Retired)

Email: madhab mjoshi43@gmail.com

\begin{abstract}
Annual methane emission from paddy fields in Nepal has been estimated based on the published secondary data for 11 years from 2000-2010. Available data were collected from the Ministry of Agricultural Development (MoAD), Department of Agriculture (DoA) and Nepal Agricultural Research Council (NARC). Green house gas emission (GHG) was estimated by using IPCC 2006 guidelines. Agricultural activities contribute directly to emissions of greenhouse gases through a variety of processes including the source categories such as enteric fermentation in domestic livestock, livestock manure management, rice cultivation, and agricultural soil management. Diverse traditional agriculture systems, unique diversities in land types and unavailability of required disaggregated data at the national level as defined by the emission factor data base (EFDB) of the IPCC 2006, were the problem encountered while calculating the emission status in this study. Annual methane $\left(\mathrm{CH}_{4}\right)$ emission from paddy fields ranged from 111.57 to 133.07 Gg over years 2000 to 2010 but it was found lowest $(111.57 \mathrm{Gg}$ ) in the year 2002 and highest $(133.07 \mathrm{Gg})$ in the year2003. In the year 2010, methane emission from paddy cultivation represented about $17.48 \%$ of cumulative methane emission both from livestock sector and paddy fields throughout Nepal. Also, some relevant policies and potential strategies towards mitigation measures of methane gas emission from paddy fields for the future in Nepal are highlighted.
\end{abstract}

Key words: methane, emission status, paddy

\section{Introduction}

Nepal has been experiencing adverse impact of climate change despite negligible contribution to global greenhouse gas emission. Drastic increase in human activities has led to the deterioration in the original harmony of the natural environments in the global surface. Climate change is a natural process but recent trends related to climate change are alarming mainly due to anthropogenic reasons. Climate change has already affected people, their livelihoods and ecosystems, and presents a great development challenge for the global community in general and for the poor people in developing countries in particular.

Agriculture is one of the major contributing sectors in Nepalese economy that shares 35.65 percentages in the GDP at constant price at 2010 and it provides employment to 65.6 percent of economically active population (MoAC, 2010). The economy of Nepal is 
largely based on subsistence agriculture and livestock which occupies a pivotal position in the national economy and in the agriculture sector. Livestock sector contributes about $9 \%$ in the national GDP and about 26\% in AGDP (MoAC, 2010). Agriculture is sensitive to short-term change in weather and to diurnal, seasonal, annual and long term variation in climate. Increases of greenhouse gases (GHGs)or greenhouse effects or global warming or air temperature rise in the atmosphere directly affect the food supply and access through their direct and indirect effect on crops, soils, livestock, fisheries, diseases and insect pests. The increase in atmospheric $\mathrm{CO}_{2}$ concentration promotes the growth and productivity of crops, while other considerable factors like land use change, availability of water for irrigation, frequency and intensity of soil organic transformation, soil erosion and decline of arable areas is likely to pose threats to the production. The increased level of GHGs has created a greenhouse effect which subsequently altered precipitation patterns and global temperature around the world. Although methane is a rare gas in the atmosphere, however, its existence and increased concentration in recent years has proven to have a close relation with the problems of "greenhouse effect" that will lead to the rising of temperature on the global surface. "Destruction of ozone layer" and rising of ultraviolet rays in the atmosphere are menacing the life on earth. Flooded rice is considered to be one of the major biogenic methane sources (Huang, 1991). Generally, methane in the paddy soil is directly released to the atmosphere through rice plants.

Rice produces greater yields when it is grown in the flooded versus unflooded soil (DeDutta, 1981) The practice of submergence results in greater suppression of weed growth, higher efficiency in the utilization of added nitrogen, and better insect and weed control with granular chemicals. Since rice is the main staple food crop in Nepal and its cultivation need to be continued for food security and economy of the people at large. However, increased awareness towards improved management practice of rice cultivation that minimizes the production of methane gas is highly needed to all the farmers in Nepal. Similarly, desirable environmental friendly technologies in Nepalese perspective such as eco-farming, integrated plant nutrition systems, integrated pests management, water harvesting technology, crop diversification, and biodiversity conservation and agro forestry equally hold importance (Joshi, 2000).

Previous reports indicate that GHGs emission in agriculture in FY 1994/95 was $867 \mathrm{Gg}$ of $\mathrm{CH}_{4}$ and $29 \mathrm{Gg}$ of $\mathrm{N}_{2} \mathrm{O}$ (MoPE, 2004). Other studies reported that 490 tons of $\mathrm{CH}_{4}$ is emitted from domestic animal (Sharma, 2000). Reliable and latest inventory on GHGs emission in Nepal from agriculture sector was lacking. Therefore, this part of the assessment study was attempted in order to document the current emission status of methane from rice cultivation in Nepal and suggest its mitigation strategies for the farmers in future. 


\section{Data collection methods and approaches}

An Inception Workshop was organized by the Alternative Energy Promotion Centre (AEPC) on February 2013 to finalize the process of data collection, compilation, analysis and reporting. The methods concluded by the workshop were followed, which are listed below:

- Authentic secondary data sources on agriculture commodities were taken from Statistical Information on Nepalese Agriculture from FY 2000 to 2010 published by Ministry of Agricultural Development (MoAD). MoAD has compiled the district level data sources through DoA, DoLS every year. Annually, concerned district offices collect data from the grass root level by conducting surveys/sampling/crop cutting methods in major field crops/livestock commodities. Those data were categorized, grouped and synthesized according to the physiographic division of the country as mountains, hills and Terai. In addition, reports from Central Bureau of Statistics (CBS) were used to verify them.

- Information on length of growing season of rice, total duration of different crops in Mountains, Hills and Terai were compiled and synthesized from the group discussion with concerned experts of NARC/ DoA as well as published reports. Similarly, field application of manures in rice crop was derived from the discussion of concerned soil experts of NARC. The information thus obtained were synthesized as the rate of application of manure per ha for rice, maize and potato crops in mountain, hills and Terai.

- Default emission factors as given in Emission Factor Data Base (EFDB) of IPCC Guidelines for National Greenhouse Gas Inventories have been used for calculating the GHGs emissions.

- A Technical Working Group (TWG) including the technical experts from DoA, DoLS, NARC and MoAD were formed by AEPC in order to facilitate the task. The compiled data were discussed and verified in a series of TWG meetings. Also, the way forward as suggested by the TWG members were followed to address the existing data gaps.

- The inputs by the stakeholders from various institutions were incorporated after a stakeholder's workshop organized on early October 2013 and the report was finalized.

The GHGs emissions from the agricultural sector are estimated based on secondary data. The data were collected from the Ministry of Agricultural Development (MoAD), Department of Agriculture (DoA) Department of Livestock Services (DoLS) and Nepal Agricultural Research Council (NARC). The detail on data collected is presented in Table 1. The data were collected from the Ministry of Agricultural Development (MoAD) and Nepal Agricultural Research Council (NARC). The detail on secondary data were collected were further processed for 11 years, 2000-2010. Data were processed in terms of 
harvest area under irrigated paddies and rain-fed rice, rice areas under the mountain, hills and Terai regions, average cultivation duration of rice in days and major cropping patterns.

\section{Results and discussion}

\section{Trend in paddy cultivation area from $2000-\mathbf{2 0 1 0}$}

The average paddy cultivation area in Nepal stands around 1.52 million ha $(0.06,0.38$ and 1.08 million ha respectively in mountain, hill and terai). There is no distinct trend in change of the paddy cultivation area in Nepal as it is a monsoon based crop. Nevertheless, in year 2006, there was noticeable decline in paddy cultivated area (Figure 1). As compared to 2005, the paddy cultivated area in 2006 dropped by nearly $7.1 \%$. The maximum area coverage by paddy cultivation was in year 2003 (1.56 million ha). The distribution of irrigated and rainfed paddy cultivation area as well as the distribution of rice area in the mountain, hills and Terai areas for 11 years were the basis of the assessment of GHGs.

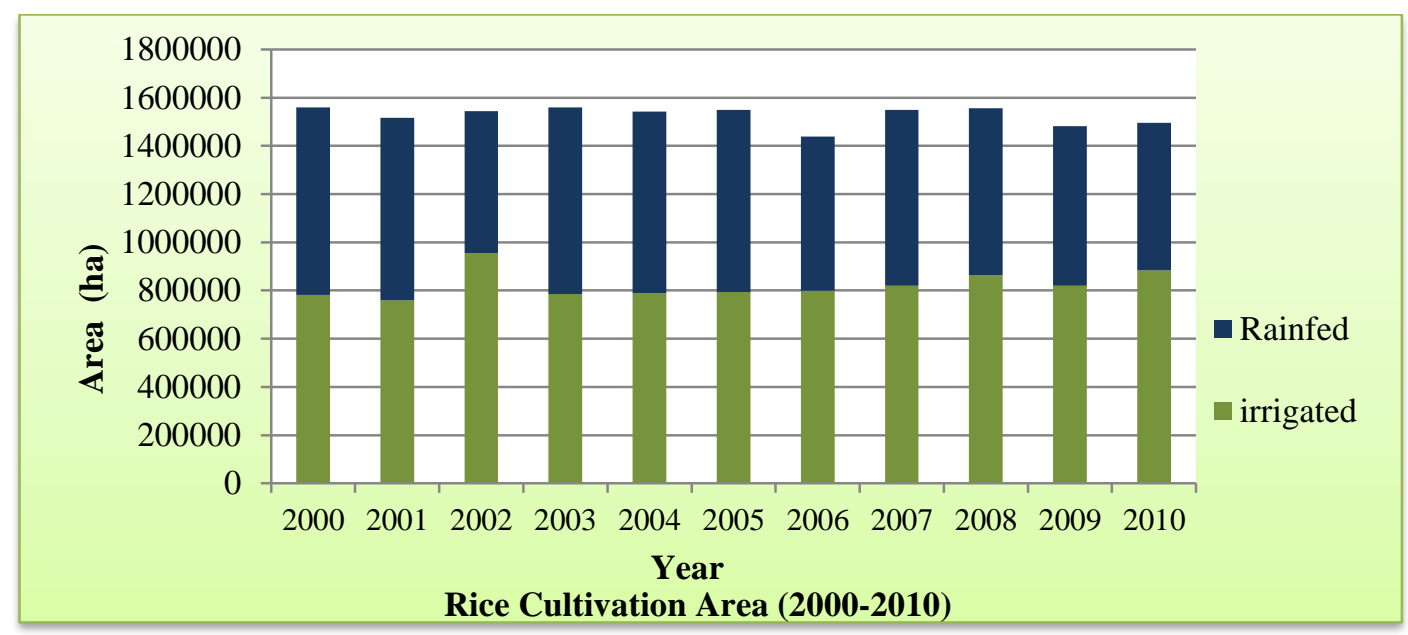

Figure 1. Trend in paddy cultivation area

\section{Methane (CH4) emissions from Paddy cultivation}

Paddy cultivations are mainly done under flooded condition. Anaerobic decomposition of organic materials take place in flooded rice field because the flooding limits the oxygen supply to the deeper layers producing methane. In Nepal, rice area is disaggregated only as irrigated and rain-fed categories. Soil type, temperature, and rice cultivar also affect $\mathrm{CH}_{4}$ emission rate. $\mathrm{CH}_{4}$ emission from paddy cultivation is estimated at $131.75 \mathrm{Gg}$ in 2000 and it is $127.13 \mathrm{Gg}$ in 2010 (Table 1). Annual variation of annual $\mathrm{CH}_{4}$ emissions from paddy cultivation is shown in Figure 2. Annual emission of methane from rice fields was found to be only at $17.48 \%$ of the grand total of $727.41 \mathrm{Gg}$ of cumulative $\mathrm{CH} 4$ emission both from rice cultivation and livestock sector during 2010. Annual methane $\left(\mathrm{CH}_{4}\right)$ emission from paddy fields showed within a range from 111.57 to $133.07 \mathrm{Gg}$ over years, 2000 to 2010 . 
The lowest emission of $111.57 \mathrm{Gg}$ was found in the year 2002 and the highest emission value of $133.07 \mathrm{Gg}$ was found in the year 2003 .

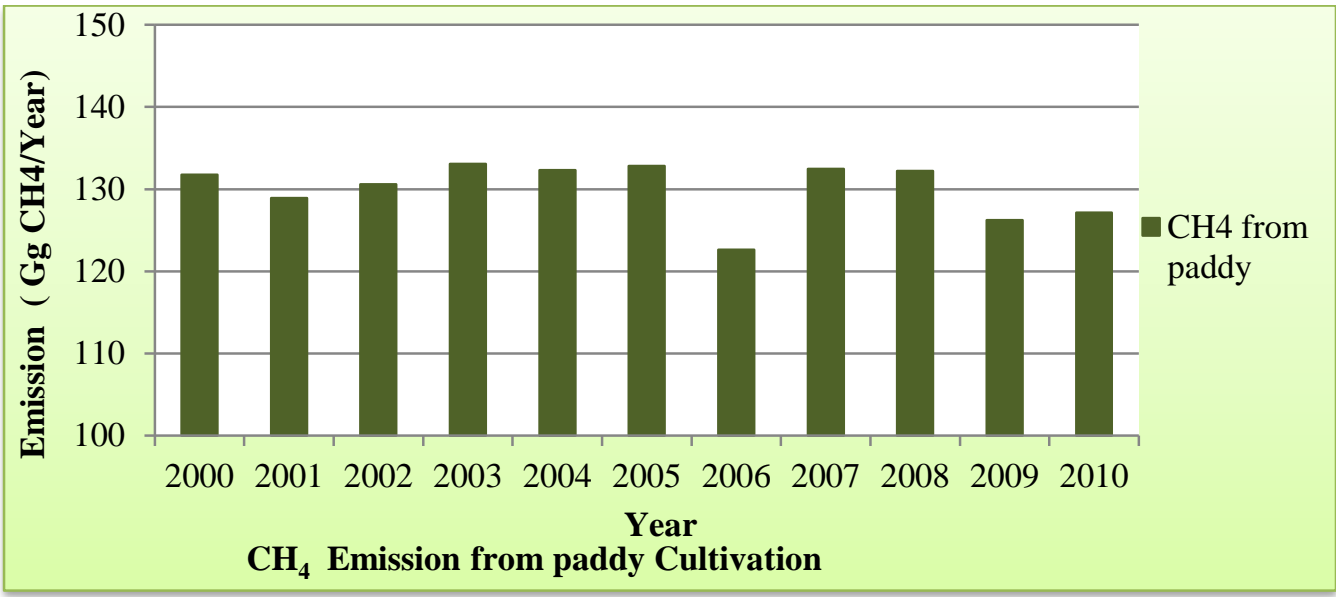

Figure 2. $\mathrm{CH}_{4}$ Emission from paddy cultivation

\begin{tabular}{|c|c|c|c|c|}
\hline Year & $\begin{array}{l}\text { Total } \mathrm{CH}_{4} \text { emission from } \\
\text { enteric fermentation and } \\
\text { manure management } \\
\text { from livestock raising }(\mathrm{Gg})\end{array}$ & $\begin{array}{lr}\mathrm{CH}_{4} \text { emission } & \begin{array}{r}\text { only } \\
\text { from }\end{array} \\
\text { cultivation } & \text { fields } \\
(\mathrm{Gg}) & \end{array}$ & $\begin{array}{lr}\text { Grand total of } \\
\text { CH4 emission both } \\
\text { from } & \text { paddy } \\
\text { cultivation } & \text { and } \\
\text { livestock } & \text { raising } \\
(G g) & \end{array}$ & $\begin{array}{l}\text { Percent of total } \mathrm{CH} 4 \\
\text { emission from paddy } \\
\text { fields only }(\mathrm{Gg})\end{array}$ \\
\hline 2000 & 511.91 & 131.75 & 643.66 & 20.47 \\
\hline 2001 & 496.64 & 128.92 & 625.56 & 20.61 \\
\hline 2002 & 505.08 & 111.57 & 616.65 & 18.09 \\
\hline 2003 & 514.88 & 133.07 & 647.95 & 20.54 \\
\hline 2004 & 524.74 & 132.29 & 657.03 & 20.13 \\
\hline 2005 & 533.83 & 132.82 & 656.48 & 20.23 \\
\hline 2006 & 546.51 & 122.64 & 669.15 & 18.33 \\
\hline 2007 & 558.27 & 132.46 & 690.73 & 19.18 \\
\hline 2008 & 582.19 & 132.21 & 714.39 & 18.51 \\
\hline 2009 & 587.22 & 126.22 & 713.44 & 17.69 \\
\hline 2010 & 600.28 & 127.13 & 727.41 & 17.48 \\
\hline \multicolumn{5}{|c|}{ Source: RIMC and SiDeF, 2013} \\
\hline
\end{tabular}

\section{Mitigation measures on methane gas emission from paddy fields in Nepal}

Some of the suggested policies and strategies for the immediate future in Nepal are (RIMC and SiDeF, 2013, MOE, 2011, Gautam et al, 2011) as follows:

- Development of national strategies or action plans, policies and measures, and capacity building

- Agriculture sector must be climate-smart to successfully tackle current food security and climate change challenges

- Awareness raining among the rice producers on methane gas emission 
- Implementation of national policies and measures and national strategies

- Technology development and transfer and results-based demonstration activities and evolving into results-based actions that should be fully measured, reported and verified

- Mitigation measures must be in the context of farmers' decision making

- Improve agronomic practices, crop diversification and crop rotation with legumes

- Increase awareness among farmers on soil health, soil chemistry and emission of GHGs

- Promotion of conservation tillage systems in rice crop as well

- Promotion of alternate drying and wetting of rice fields to mitigate $\mathrm{CH} 4$ emission and increase water use efficiency

- Promotion of short duration and drought tolerant rice varieties recommended

- Promotion of leaf color chart on nitrogen input needs in rice fields

- Promotion of adaptation measures which includes all activities that help people and ecosystems reduce their vulnerability to the adverse impact of climate change and minimize the costs of natural disasters.

\section{Acknowledgement}

This paper is extracted from the report of "Formulation of Low Carbon Economic Development Strategy (LCEDS) for Nepal: Phase 1: Data Collection and Analysis" jointly prepared by Rural Infrastructure and Management Consultant (RIMC) and Sustainable Infrastructure Development Foundation (SIDeF) and submitted to Alternative Energy Promotion Centre (AEPC) in October 2013. The author is indebted to then Technical Working Group (TWG) Coordinator, Dr. Ramita Manandhar and TWG members from MoAD, DoA, DoLS and NARC for their technical support and guidance to fill-up data gaps and in deciding the use of default emission factors and their values for Nepal.

\section{Reference}

CBS. 2010. Statistical Year Book of Nepal, 2010.

DeDutta, S K. 1981. Principles and practices of rice production. John Willey and Sons, A Willey Interscience Publication. 618 p.

Gautam, AK; SK Rai; and PK Pokharel. 2011. Climate change impact on agriculture/Livestock in Nepal and its mitigation and adaptation measures, Gurung TB, Pokharel PK and Wright L. (eds.), p. 136-144, In: "Climate change: Livestock sector vulnerability and adaptation in Nepal", Proceedings of consultative technical workshop on Kathmandu, Nepal. NARC, Kathmandu. 156 pp.

Huang, SN. 1991. Production and emission of methane from experimental paddy soils. Published by Taiwan provincial Taichung district, Agricultural improvement station, Changhua, Taiwan. Special Publication No. 22, 1991. 
IPCC. 2006. IPCC Guidelines for National Greenhouse Gas Inventories, Prepared by the National Greenhouse Gas Inventories Programme, Eggleston H. S., Buendia L., Miwa K., Ngara T. and Tanabe K. (eds.). Published: IGES, Japan.

Joshi, M. 2000. Impact of Agricultural Practices on Environmental Sustainability in Nepal. A Country Paper presented at the Seminar. p. 222-240. In, Qureshi, R. H. (ed.) Report of an APO Seminar on Impact of Agricultural Practices on Environmental Sustainability held in Tokyo, Japan from 613 September 2000. (SEM-21-00).APO,

MoAD/MOAC. 2000 - 2010. Statistical Information on Nepalese Agriculture from F. Y. 2000/01 to 2010/11. Ministry of Agricultural and Cooperatives, Government of Nepal, Singh Durbar, Kathmandu, Nepal.

MoE. 2011. Status of climate change in Nepal. Ministry of Environment (MOE), Government of Nepal, Singh Durbar, Kathmandu, Nepal. January 2011.

MoPE. 2004. Nepal Initial National Communication to the Conference of the Parties of the United Nations Framework Convention on Climate Change July, 2004 Ministry of Population and Environment, Kathmandu, Nepal

NARC. 2010. Released and Registered Crop Varieties in Nepal 1960 - 2010. Published by CPDD, NARC, and Khumaltar.

RIMC and SIDeF. 2013. Formulation of low carbon economic development strategy (LCEDS) Phase I. Final Report. Vol 5. Agriculture Sector. October, 2013.

Sharma, B. 2000. Livestock farming and environment.P.24-28. In, Agriculture and Environment Millenium Issue. MOAC, Government of Nepal, Singh Durbar, Kathmandu, Nepal. 